\title{
An Efficient Procedure for Materials' Marking in Metallic Constructions Industry Based on QR Codes
}

\author{
Simona Riurean ${ }^{1, *}$ \\ ${ }^{1}$ University of Petroșani, 332006 Petrosani, Romania
}

\begin{abstract}
The quality standard SR EN 1090:2012 requirements enforce a maximum consistency both on the metallic construction manufacturing process and during all the additional stages till the construction site becomes a final product ready to be used. Any lack of attention during this complex manufacturing process might drive to different classes of damage consequences due to minor or major nonconformities. Therefore, among other important procedures, I refer here to the importance of marking both the raw materials (as part of the final product) and leftovers (as part of future work) resulted from the cutting process. I propose in this paper a specific database and a simple marking procedure based on QR codes. The database consists of detailed descriptions of all kind of metallic materials with different shape, structure and quality as well as all important information extracted from the quality certificate 3.1. that accompanies the goods once they arrive into the manufacturer's storage. Since the standard underlines the necessity to identify any material during work processing, the system allows conversion of large text with important data into a QR code that can be scanned and therefore the material quickly identified into the manufacturer's workshop.
\end{abstract}

\section{Introduction}

The steel structures manufacturers must meet the requirements of European standard SR EN 1090:2012 [1] in order to be allowed to sell on European market and more important stay competitive on a quite demanding market. As in all the other industries, the process of implementation of the European standard 1090 in metallic structure company is a long and difficult one with many demanding prerequisites starting with a proper Factory Production Control (FPC) process to the CE marking on final products. FPC includes an extended documentation that comply with the internal control procedures during the manufacturing process. Metallic manufacturers must already have implemented ISO 9001, 14001 and 18001 as well as SR EN ISO 3834 (welding quality management) in order to be able to develop a proper FPC according to SR EN 1090 requirements [2-3].

All the internal control procedures use documented procedures (documented information) and policies on systematic quality assurance requirements and provisions consistent with the

\footnotetext{
* Corresponding author: simonariurean@upet.ro
} 
requirements of the standard SR EN 1090. FPC's emitted, according to SR EN 1090:2012, has to provide an effective way to ensure that all the finished products fulfil a set of essential features.

SR EN 1090 is a harmonized standard product for the manufacturers covered by the Construction Products Directive (CPD 89/106/EEC) which regulates the performance requirements of steel and aluminium structures. The standard specifies conformity to product requirements structural components in terms of strength, stability, health and security at work, sustainable development and environment protection. This is done by means of conformity assessment on manufacturing specifications, design features and structural analysis of the product [4].

SR EN 1090 covers products series and non-series of structural steel and aluminium components used in construction. The components can be made of semi-hot or cold-rolled semi-finished products or other technologies. They can be flat products, profiles, solid rods, cast, steel and aluminium castings, protected or unprotected against corrosion by coating the surface with dye or zinc protection.

$\mathrm{CE}$ marking accompanying the metallic structures is based on a large number of documents certifying a rigorous internal control in the manufacturing process. These documents consist of lots of data precisely underlying all stages of project development starting with the raw materials supply till final product delivered to the final customer. The main objective of this paper is to present a simplified yet efficient marking procedure for a fast and accurate identification of raw materials both in warehouse and production facilities in order to avoid any improper use. Any improper use of the raw materials can be origin of major nonconformities that is possible to lead to incommensurable financial losses, accidents and even human losses.

In order to be able to know exactly the kind of material returned into the warehouse following different stages of the manufacturing process (cutting process for sheets, beams or pipes, for example), they must have the appropriate marking with at least information regarding its type and quality (according to the quality certificate that initially accompanied the raw material delivered by the supplier company).

With the aim of developing a fast and reliable marking procedure that is correct and efficient all the time in the manufacturing company, I first created a database containing basic materials from standard carbon steel that can be purchased for different construction. Part of the marking procedure consists in QR code generated from de database and print on a self-adhesive label that will stick on the corresponding material. QR code contains the type and size of material, its steel grade and quality, according to 3.1. quality certificate issued by the raw materials' manufacturer. The quality certificate 3.1 is compulsory to accompany the base metallic raw materials received from the delivery company, according to the purchase order sent by the manufacturing company.

\section{Prerequisites of Factory Production Control and Classes of Execution}

According to the provisions of art. 17 par. (5) of Regulation (EU) No. 305:2011, since 01 July 2014, all manufacturers of steel structures, carbon steel or aluminium are forced to deliver the CE marking to all structural steel final project with a structural role, due to the harmonized European standard SR EN 1090-1 + A1: 2012 and SR EN 1090-2 + A1: 2012 that refers to execution of steel structures and aluminium structures. Part 1 refers to requirements for conformity assessment of structural components (includes Amendment A1:2011), Part 2 refers to the technical requirements for steel structures and Part 3 refers to technical requirements for aluminium structures. 
Any metallic structures manufacturer company must hold a FPC compliance certificate issued by a Notified Body on the basis of which he may issue the Declaration of Conformity and may attach the CE Mark to the final product. The conformity assessment shall cover the manufacturing characteristics and, where appropriate, the design characteristics. If the assembly of the elements is done by welding, the manufacturer must also implement all the welding requirements mentioned in the SR EN ISO 3834 series of standards (depending on the class of construction).

To obtain this certification a long and laborious process is developed, which involves a complex audit performed by an external Certification Body, and then a continuous surveillance during the period of possession of the certificate is conducted by the same Certificated Body.

The possibility of FPC's implementation in a company is determined by two main factors: - Existence of $(i)$ qualified welders (according to DIN EN 287-1 - Steel / ISO 9606-2 Aluminium), (ii) welding inspectors (EWS/EWT/EWE, depending on the EXC execution class) and (iii) qualified personnel for non-destructive tests.

- Qualification of welding procedures (i) Recording Welding Procedure Qualification (WPQR), (ii) Welding Procedure Specification (WPS) and (iii) Testing instructions for welding seams.

The most important specifications in any metallic structure project refers to the categories of consequences, categories of stress and production categories.

The categories of consequences (CC) (EN 1990: 2002 Annex B) defines human harmful consequences, economic losses and environmental damage.

Categories of request (CR) (EN 1090-2 table B1) determines the type of stress. It is divided into: static / dynamic stresses, seismic activities, and fatigue behaviour.

Production categories (PC) (EN 1090-2 table B2) defines the categories of production. They are broken down in steel quality, product stability and similar purposes.

Different combination of the specification above result in specific execution class, from EXC 1 (least demanding) to EXC 4 (with extreme strict quality requirements), according to table 1 .

Table 1. Type of categories that defines execution class

\begin{tabular}{|l|c|c|c|c|c|c|c|}
\hline \multicolumn{2}{|l|}{ Categories of Consequences } & \multicolumn{2}{|c|}{ CC1 } & \multicolumn{2}{c|}{ CC2 } & \multicolumn{2}{c|}{ CC3 } \\
\hline Categories of Request & CR1 & CR2 & CR1 & CR2 & CR1 & CR2 \\
\hline $\begin{array}{l}\text { Production } \\
\text { Categories }\end{array}$ & PC1 & EXC1 & EXC2 & EXC2 & EXC3 & EXC3 & EXC3 \\
\cline { 2 - 8 } & PC2 & EXC2 & EXC2 & EXC2 & EXC3 & EXC3 & EXC4 \\
\hline
\end{tabular}

No matter the execution class prerequisite in the project of a metallic steel structure, the internal procedures regarding marking of the material is the same with high requirements.

\section{Basic Raw Materials Marking and CE Marking}

According to EN 1090, the basic raw materials must meet the conditions specified in the project (brand, quality class), be accompanied by the material suppliers' quality certificates and marked on each plate, flat strip, profile, pipe etc., steel mark, quality class, batch and batch number. The use of any unlabelled base metallic materials is not allowed. The steel construction according to EN 10025 uses S $355 \mathrm{~J} 2$. The characteristics of the steels must be explicitly required in the material order sent to the supplier and only marked parts along with the conforming quality certificate (3.1 and/or 3.2) are to be considered as acceptable for production. The surface and interior defects of laminates and sheets must meet the requirements of EN 10163-2, Class A, Subclass 2 and welding additive materials must comply with SR EN 14341; SR EN 14171 and SR EN 760. 
The CE marking concept has, since 1985, the same form as in present. CE indicates that the products launched by the manufacturer are guaranteed and have been tested in order to be according to the industry specific European standard EN 1090:2012. Only companies that have been audited and their manufacturing processes accepted according to standard's requirements, can use the CE marking. The CE marking is not an indication of the products' European origins, but rather a guarantee of high quality but also a prerequisite for entering on the European markets [4,5].

\section{The Proposed Internal Marking Procedure}

Although both basic raw materials and CE marking are cleared defined in 1090:2012 standard, the internal marking procedure is part of the manufacturing internal procedures specific for each company. Therefore, the marking procedure I propose refers to the basic raw materials resulted from cutting process in the company in order to be used for current or further projects.

I must underline the importance of the correct identification of the materials to be used in metallic structures according to the execution class imposed by the customer in order to avoid any nonconformity and therefore any further consequences because of the lack of required level of quality for the final product.

\subsection{Database of the raw materials}

In order to automate the fast identification of materials in the warehouse and in the production sites, a database has been designed (see figure 1) consisting of basic raw metallic materials, according to the standard manufacturing dimensions, the brand of steels and their quality [6].
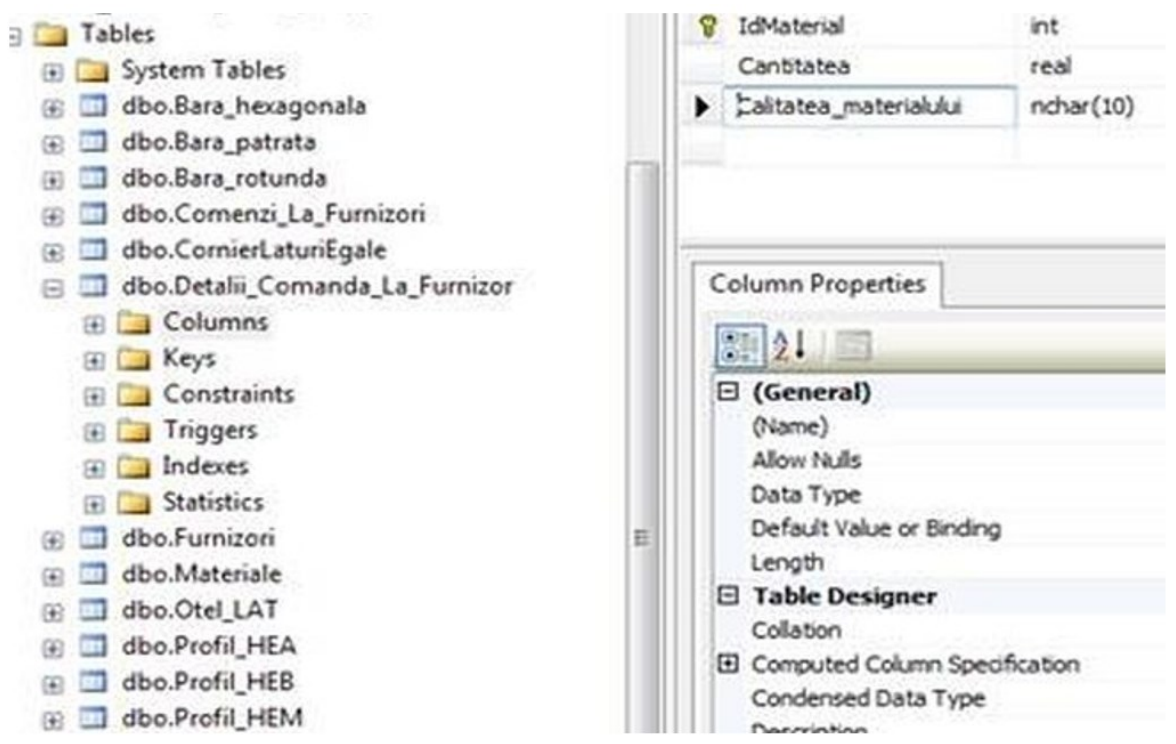

Fig. 1. Database for all types of steel metallic materials

For a proper identification and classification in categories and subcategories, both the quality standards and the steel grade are important to be part of the database.

The quality standards for steel materials in constructions are, according to EN 100252:2004: S185, S235JR, S235JO, S235J2, S275JR, S275JO, S275J2, S355JR, 355JO, S235J2, $\mathrm{S} 355 \mathrm{~K} 2$. The alphanumerical symbolisation consists of the steel grade (S185, S235, S275, 
S355) and its corresponding quality class (JR, JO, J2, K2). The steel grade S refers to steel group - for constructions and number 185, 235, 275 or 355 represents minimum value of the expressed flow limit.

Steel grades differ from each other due to mechanical characteristics. Each steel grade has multiple quality classes. For example, the minimum value of burst energy at impact bending due to a shock event defines JR $\left(27 \mathrm{~J}\right.$ at $\left.+20^{\circ} \mathrm{C}\right)$, JO $\left(27 \mathrm{~J}\right.$ at $\left.0^{\circ} \mathrm{C}\right)$, J2 $\left(\mathrm{J} 27\right.$ at $\left.+20^{\circ} \mathrm{C}\right)$ and $\mathrm{K} 2\left(40 \mathrm{~J}\right.$ at $\left.-20^{\circ} \mathrm{C}\right)$. The quality classes underline the steel behaviour due to the welding procedures in order to avoid any fragile breaks. Regularly JR, JO, J2 and K2 support any welding procedure. Welding affordability increases from JR to K2. Therefore, not all steel materials are welding affordable. The highest carbon percent the lowest welding affordability.

I considered important to emphasize these technical characteristics to make a proper substantiation of my work. Base material steel is quite divers and any technical characteristic can change its destination. Therefore, a clear, complete identification of the material on shelf and complete description in database is essential. Figures 2 and 3 show the database created with basic steel materials (beams, sheet, pipes and so on).

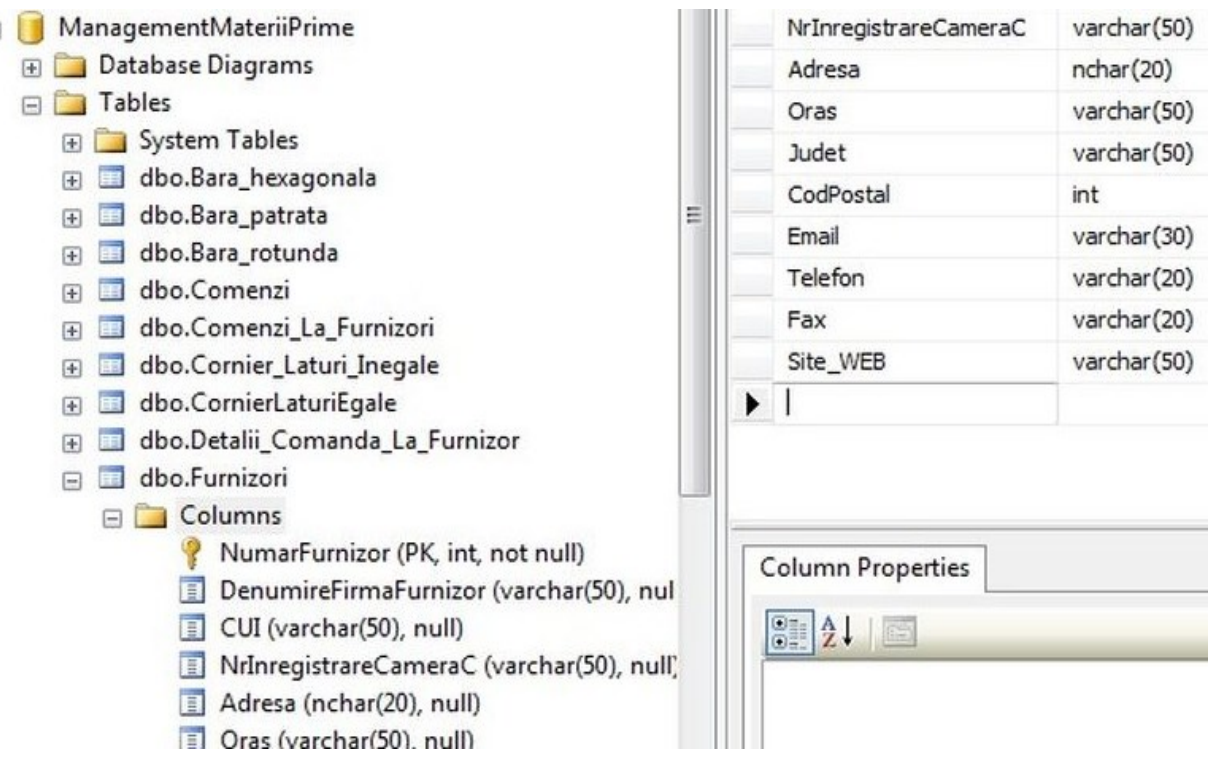

Fig. 2. Database with data from the delivery company

Another challenge in data base design consists in unity of measure. Because the data stored for of all types of materials in the warehouses is based on the kilogram unit, and the technical building projects contain lists of material in the meters, is always necessary to convert them from one unit to other. Therefore, database has to allow identification of materials in any of the previous mentioned units. The database should contain beside type of material with dimensions (meters and kilograms), the steel grade, material quality, the batch and the corresponding batch of the quality certificate attached to the purchased materials. 


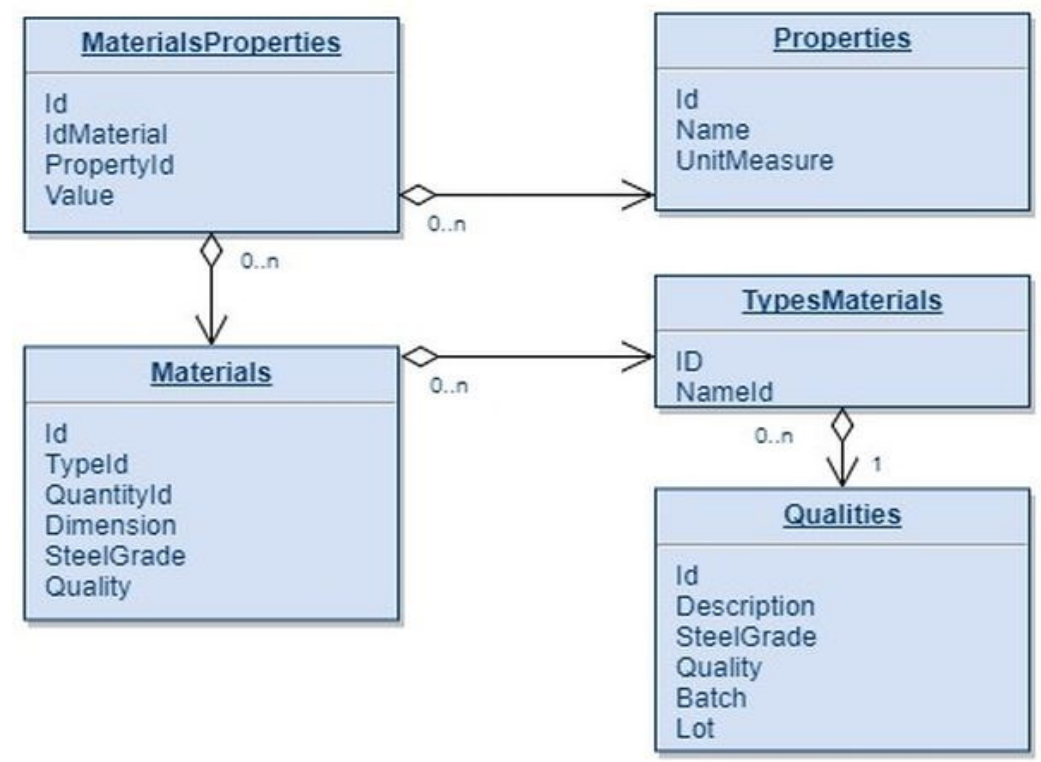

Fig. 3. Database Diagram Materials_Cod_QR

The QR code is going to be automatically generated, extracting from the database just the necessary information to be print on the self-adhesive label. The diagram of tables for $\mathrm{QR}$ code generations is presented in figure 3 .

\subsection{QR code generator}

In order to generate the $\mathrm{QR}$ code from the database, the following steps have been taken:

1. A Windows Presentation Foundation project is initialized. Here, data will be shown in a window. The correct data picking, their position and components configuration is possible due to the default designer and XAML language. Different properties related to data appearance can be settled or changed here. $\mathrm{C \#}$ is the base for the logical aspect of application development. In figure 4, the project initialization is shown [7].

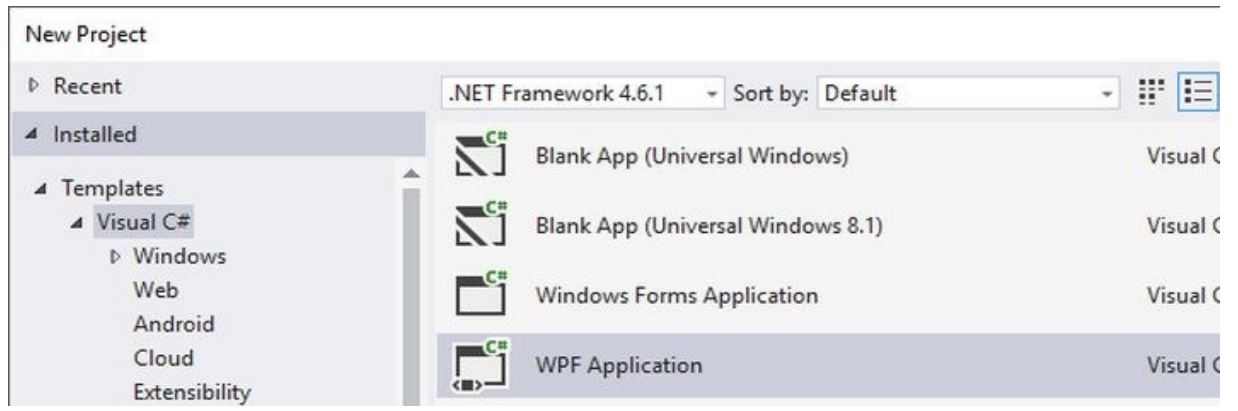

Fig. 4. Project Initialization

2. Using NuGet library manager, I attach to the project, the following:

- Entity Framework - the platform for accessing the database as a representation of each table in one class that is then used in LING language in order to perform efficient queries avoiding to use any native SQL syntax [8]; 
- $\quad$ ZXing.Net - this library allows to encode string data in QR codes [9].

Classes are going to be organized as layers: database access layer, data manipulation algorithm layer and user interface layer. In order to access the database, the ADO.NET Entity Data Model is added to generate classes corresponding to tables in database. ADO.NET is an Object Relational Mapper that automatically generates links between database and the aimed classes. Data is using object-oriented programming. Figure 5 shows the Entity Data Model, figure 6 present the type of Data Entity Model, connection with the database is shown in figure 7 and tables selected for the QR code generation are presented in figure 8 .

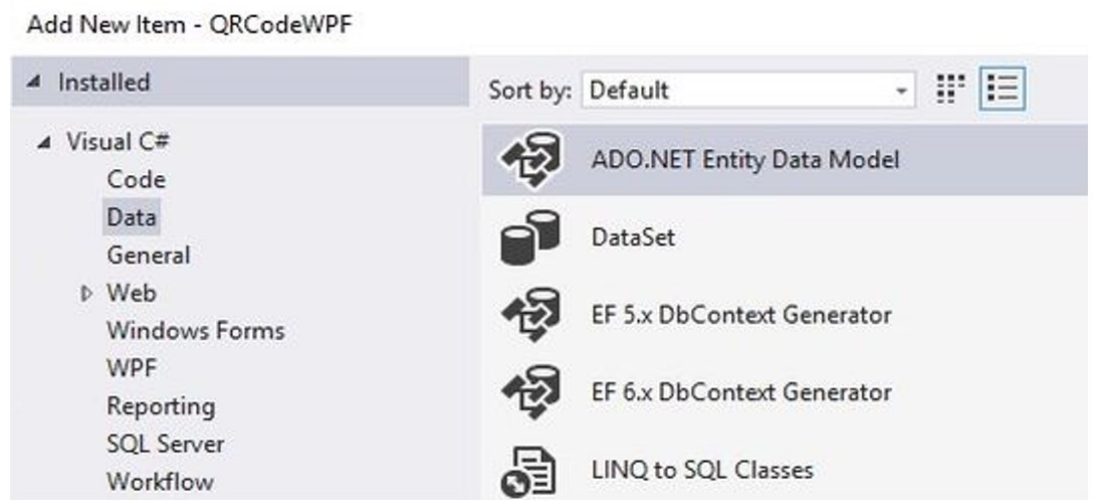

Fig. 5. Entity Data Model

Entity Data Model Wizard

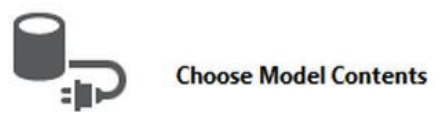

What should the model contain?

\begin{tabular}{|c|c|c|c|}
\hline 跣古 & 沿占 & 偪 & 包 \\
\hline $\begin{array}{c}\text { EF Designer } \\
\text { from } \\
\text { database }\end{array}$ & $\begin{array}{c}\text { Empty EF } \\
\text { Designer } \\
\text { model }\end{array}$ & $\begin{array}{l}\text { Empty Code } \\
\text { First model }\end{array}$ & $\begin{array}{c}\text { Code First } \\
\text { from } \\
\text { database }\end{array}$ \\
\hline
\end{tabular}

Fig. 6 . Type of Data Entity Model

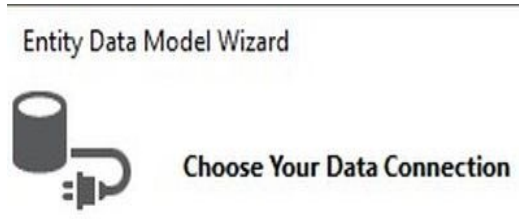

Which data connection should your application use to connect to the database?

desktop-1q0tv3n/sqlexpress.Materiale_Cod_QR.dbo

New Connection...

Fig. 7. Connection to the database 
Entity Data Model Wizard

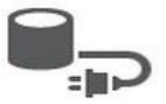

Choose Your Database Objects and Settings

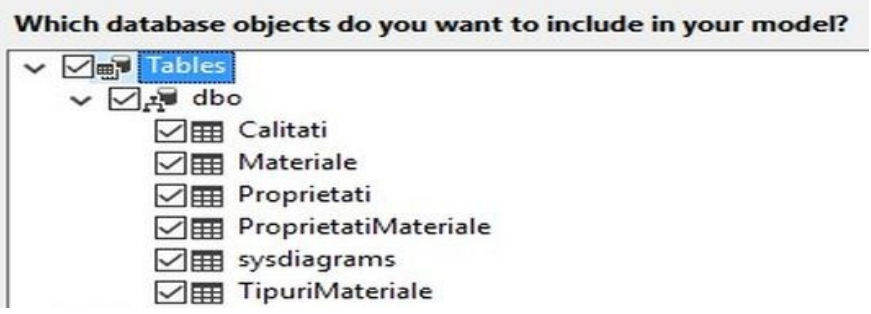

Fig. 8 . Tables selected for the QR code generation

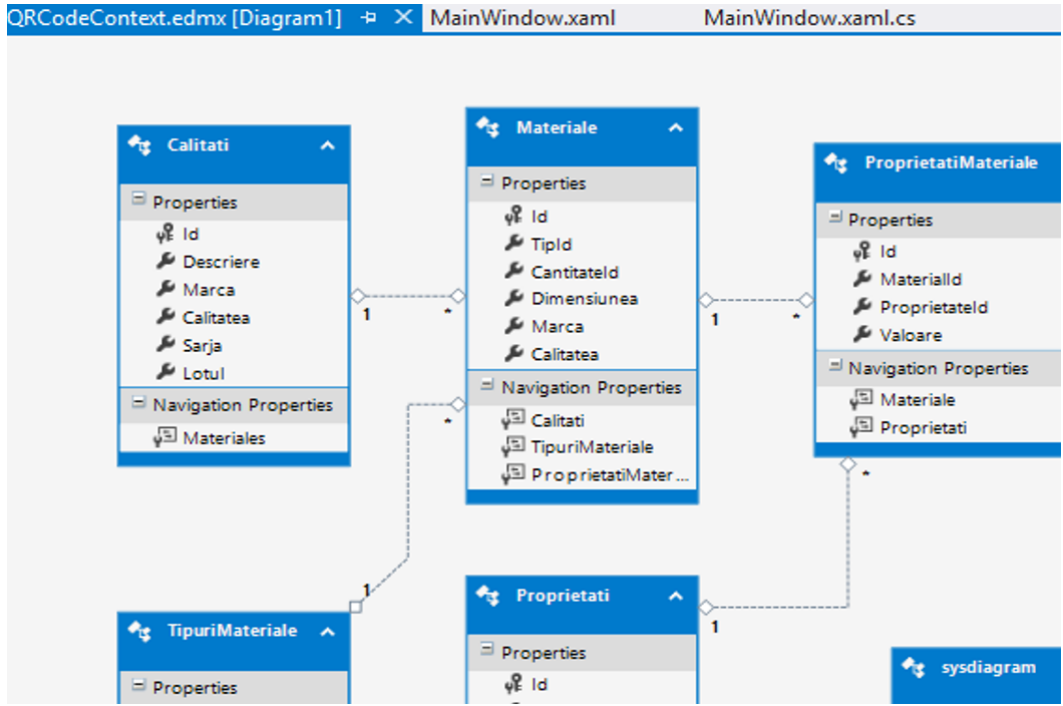

Fig. 9. The model generated

The additional table "sysdiagram" is automatically generated (figure 9) and has no connection with the logical construction of the project, therefore is ignored. The generated model keeps the correct correspondence between data types in SQL and those in C\# (as for example „varchar” and „string”) [10-11].

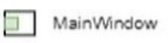

Database:
\begin{tabular}{|l|}
\hline HEA \\
\hline 100 \\
\hline S355 \\
\hline J2 \\
\hline Generate barcode \\
\hline
\end{tabular}

Fig. 10. User interface with the $\mathrm{QR}$ code generated 
According to user interface, the QR codes are automatically generated (figure 10), print on self-adhesive labels and then applied on the metallic materials both in the production halls metalworking company and in its warehouses.

The QR code generated consists of all necessary important data in order to proper identify any material left from current order, kept in stock, that is about to be used for further projects.

\subsection{QR code scanner}

Any type of metallic material with an accurate marking label can be scanned. Since a Quick Response (QR) code can be easily scanned using a smart phone, I considered this marking procedure a useful one since both hardware (smart phone) and software (free apps) are generally available in any company without any further costs. Once the QR code scanned, the string of data stored can be read as text and further copy or send as SMS to the concerned department in company [12].

The QR code example scanned as seen in figure 11, has its material name (HEA - beam type), dimension (100), as well as all information regarding the steel type (S355 - steel group and $\mathrm{J} 2-$ its quality class).
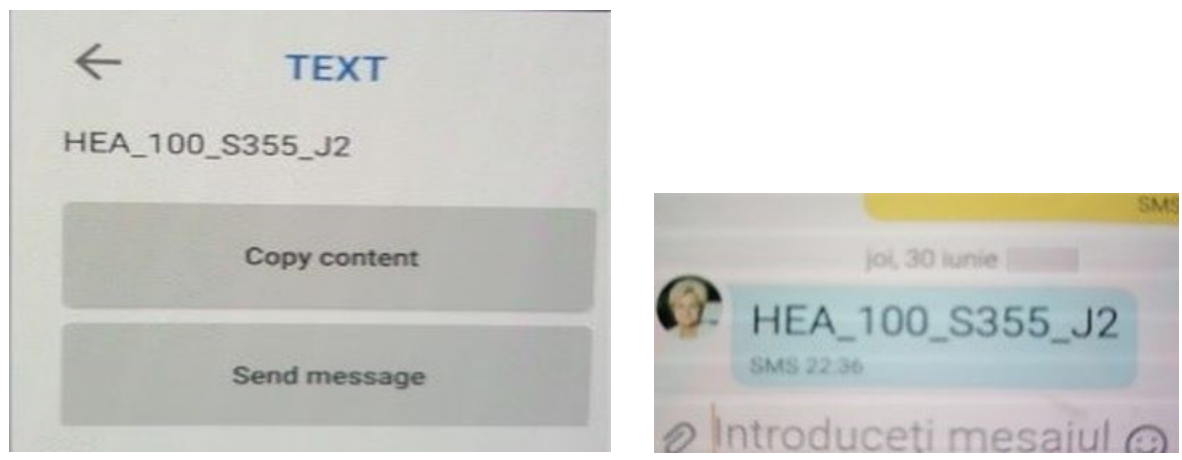

Fig. 11.QR code scanned, converted in text and send by SMS

\section{Conclusions}

This paperwork addresses an efficient and low-cost method for a fast-internal marking procedure applied to the materials resulted from technological work in factory (as cutting, for example) that has to comply with a large number of regulations in order to meet the quality requirements imposed by the SR EN 1090 standard.

For an automated work and fast identification of the materials in the warehouse and especially in the production sites, a database of these materials has been designed, according to their names and standard sizes, the type of steels and their quality.

This database contains most types of carbon steel materials that a metalworking company can be supplied with in order to manufacture metallic structures according to different projects. Even small-scale projects contain hundreds if not thousands of spare parts that have to be processed. All these items must bear an identification from the supplier company at delivery, according to standard in force. However, after processing in factory, the resulted spare parts to be used in the current project, as well as the parts stored in warehouses, or left into the manufacturing halls, in order to be used in further project, have no more marking attached. 
I have analysed the possibilities of making more marking labels and propose a fast, reliable and appropriate (correct from the point of view of the requirements / results report) way of creating the markings through $2 \mathrm{D}$ QR codes.

The first and most important element taken into account was the sustainability of printed information. Labels obtained via QR codes can be read even if up to $30 \%$ of their contents are lost.

Metallic materials undergo a series of manufacturing operations, they are often handled with heavy machinery and cranes and it is possible to scratch or tear them partially. The QR code contains its own error correction, calibration, internal orientation, and self-alignment markers. In this way, it does not matter if the QR code is upside down, wrapped or on a curved surface, the message will still be read. Another reason for choosing this type of labels is that they can embed a great deal of useful information. OR codes can be easily scanned and communicated by SMS in real-time, using any smart phone, being in this way an efficient and low cost marking internal procedure for a fast identification of metallic materials in manufacturing company.

There are already on market lots of software solutions dedicated to the Warehouse Management Systems, but all of them refers to materials that are stored into the company's warehouse. Metallic materials and spare parts left from previous projects, suitable to be used for the next ones, are of tens or hundreds of kilograms and therefore moving them from the manufacturing place to the warehouse is a waste of time, effort and money. Therefore, the present solution refers to a fast, cheap and reliable identification procedure of the "metallic leftovers" in manufacturing halls, in order to avoid major material nonconformities with future possible catastrophic results. Further work aims to accommodate into the already designed database, all kind of aluminium materials and stainless-steel materials in order to cover a wider range of products for a high demanding industry, metallic work.

\section{References}

1. EU Standard 1090:2012 (https://www.en-standard.eu/din-en-1090-execution-of-steel-structures) (last accessed 19.02.2019)

2. A. Ionica, M. Leba, Check4Green Startup Case, Quality-Access to Success, 18 Supplement: 1, 338-343 (2017)

3. R. Dovleac, A. Ionica, M. Leba, 5th Review of Management and Economic Engineering International Tech Conference University Cluj Napoca, Book Series: Review of Management and Economic Engineering International Management Conference, 32-39 (2016)

4. A. J. Kallunki, Bachelor's Thesis, Centria University of Applied Sciences Bachelor Degree Programme of Industrial Management (2016)

5. A. Ionica, M. Leba, R. Dobra, 4th Review of Management and Economic Engineering International Management, Technical Univ Cluj Napoca, ROMANIA 2014, Book Series: Review of Management and Economic Engineering International Management Conference, 390-398 (2014)

6. S.M. Riurean, Tehnici de prelucrarea informațiilor - Teorie și aplicații, Editura Bren, București (2005)

7. O.M. Zlatibor, Conferința Asociației de Sudură ASR Reșiţa (2011).

8. M. MacDonald, Apress Publisher, 1078 ,doi: 10.1007/978-1-4302-4366-3 (2012)

9. D. Kulkarni, L. Bolognese, M. Warren, A. Hejlsberg, K. George (2007) (https://docs.microsoft.com) (last accessed 20.02.2019)

10. M. S. Siddiqi, (2010) (http://www.shujaat.net) (last accessed 20.02.2019)

11. Ashford, R. College \& Research Libraries News, 71 (10): 526-530 (2010)

12. A. Ionica, M. Leba, International Conference on Applied Computer Science ACS, 615-618 (2010) 